\title{
Avaliação hormonal indireta e estudo da preservação folicular em tecido ovariano autólogo transplantado para região inguinal em ratos $^{1}$
}

\author{
Álvaro Pigatto Ceschin ${ }^{2}$, Maria de Lourdes Pessole Biondo-Simões ${ }^{3}$, Beatriz Angélica Charlotte Thomaz ${ }^{4}$, Joel Totsugui $^{5}$
}

\begin{abstract}
Ceschin AP, Biondo-Simões MLP, Thomaz BAC, Totsugui J. Avaliação hormonal indireta e estudo da preservação folicular em tecido ovariano autólogo transplantado para região inguinal, em ratos. Acta Cir Bras [serial online] 2004 Jan-Fev;19(1). Disponível em URL: http://www.scielo.br/acb.

RESUMO - Objetivo: O transplante autólogo de tecido ovariano tem sido objeto de estudo de diversos pesquisadores pela perspectiva de manter a funcionalidade deste órgão, mesmo não localizado em seu sítio habitual, sendo daí removido, a fim de minimizar os efeitos causados, por exemplo, pela radioterapia. Este trabalho visa a analisar a efetividade da técnica de autotransplante subcutâneo de tecido ovariano bisseccionado em região inguinal de ratas albinas, próximo aos vasos femorais, através do estudo indireto da produção hormonal, feita pela avaliação da citologia de esfregaços vaginais e do estudo direto da viabilidade tecidual, realizado por meio da análise histológica. Métodos: Analisaram-se 30 ratas, que sofreram ooforectomia bilateral, sendo 15 delas destinadas ao controle e 15 submetidas ao transplante ovariano. Decorridos 28 dias, recuperaram-se e avaliaram-se os enxertos. As análises da citologia dos esfregaços vaginais efetuaram-se no momento 0 , ou seja, pré-transplante, e no momento 1, póstransplante, para os animais de ambos os grupos e a avaliação histológica realizou-se no momento 0 para os dois grupos e no momento 1 para os animais transplantados. Resultados: Os resultados do experimento demonstraram a viabilidade e funcionalidade dos enxertos em $100 \%$ das lâminas analisadas, isso verificado através da obtenção de esfregaços em fase de estro para todas as ratas do grupo experimento e da presença de folículos em vários estágios de desenvolvimento, observados nos enxertos recuperados, indicando diretamente a viabilidade do tecido ovariano. Conclusão: o transplante de tecido ovariano é uma alternativa viável, nas condições do experimento, para a preservação hormonal e folicular, em ratas.
\end{abstract}

DESCRITORES - Ovário. Transplante. Hormônios. Estrógenos. Progesterona. Ratos.

\section{Introdução}

Apesar da evolução na prevenção do câncer genital feminino ter melhorado muito nos últimos anos, é ainda alta a incidência destes tumores. Os protocolos terapêuticos se tornaram mais e mais agressivos com o uso de quimio e radioterapia, o que melhorou a efetividade ${ }^{1}$. A radioterapia é particularmente letal às células em mitose. Tumores pélvicos como os de ovários, reto, colo uterino, vagina e vulva apresentam bons resultados com esse tratamento ${ }^{2}$.
Esta modalidade terapêutica tem como consequiencia, para a maioria das mulheres, a perda da função ovariana com conseqüente menopausa prematura, infertilidade, problemas coronarianos e osteoporose $^{8}$.

Os sintomas da deficiência estrogênica podem ser observados precocemente no climatério, sendo os mais freqüentes: alterações vasomotoras, ondas de calor, sudorese noturna, palpitações, cefaléias e vertigens. Sintomas psicológicos podem também ocorrer e incluem os seguintes: depressão, irritabilidade, fadiga e perda da libido.

Como tratamento, preconiza-se a terapia de reposição hormonal (TRH), que visa a diminuir os sintomas, prevenir a osteoporose e minimizar as alterações cardiovasculares devidas ao hipoestrogenismo ${ }^{4}$.

Uma promissora alternativa para diminuir as situações de menopausa precoce, causadas pelos tratamentos radioterápicos, seria o autotransplante ovariano. O enxerto subcutâneo de tecido ovariano funcional extirpado tende a preservar sua

1. Resumo de dissertação de Mestrado apresentada ao Programa de Pós-Graduação em Princípios da Cirurgia da Faculdade Evangélica do Paraná Instituto de Pesquisas Médicas.

2. Mestre em Princípios da Cirurgia, Ginecologista do Hospital e Maternidade Santa Brígida e da Clínica de reprodução Humana Felicita.

3. Doutora em Cirurgia Experimental, Coordenadora da Disciplina de Técnica Cirúrgica e Cirurgia Experimental da Universidade Federal do Paraná (UFPR), Professora Titular de Metodologia Científica do Curso de Medicina da Pontifícia Universidade Católica do Paraná (PUCPR).

4. Bioquímica da Clinica de Reprodução Humana Felicità. Mestranda da PUCPR.

5. Professor-Doutor de Patologia da UFPR. 
função, permitindo uma situação fisiológica normal e oferecendo um local mais acessível ao exame e à remoção, quando necessária ${ }^{3}$. Pesquisas indicam que ovários transplantados, em região subcutânea, em ratas podem preservar a função endócrina, mantendo a viabilidade folicular $^{3,12}$.

O presente estudo tem como proposição demonstrar a viabilidade e a funcionalidade do tecido ovariano bisseccionado autotransplantado no subcutâneo da região inguinal, próximo aos vasos femurais, em ratas.

\section{Métodos}

Neste estudo obedeceu-se à Lei Federal 6.638 e às normas do Colégio Brasileiro de Experimentação Animal (COBEA), instituição filiada ao International Council for Laboratory Animal Science.

Utilizaram-se 30 ratos fêmeas ( $\underline{\text { Rattus }}$ norvegicus albinus, Rodentia mammalia), da linhagem Wistar, com idade entre $100 \mathrm{e}$ 120 dias e peso entre 220 e 280 gramas obtidos junto ao Biotério do Instituto Tecnológico do Paraná (TECPAR).

Dividiu-se a amostra em 2 grupos com 15 animais:

- Grupo A: grupo-experimento, amostras transplantadas, submetidas à análise de citologia vaginal nos momentos 0 e 1 e avaliação histológica em ambos os momentos. Sendo denominado momento 0 o dia da ooforectomia e momento 1 , a avaliação 28 dias após.

- Grupo B: grupo-controle, amostras não-transplantadas, submetidas à análise de esfregaço vaginal nos momentos 0 e 1 e avaliação histológica no momento 0 .

Sob anestesia inalatória de éter etílico colheu-se o muco vaginal e fez-se o esfregaço em lâmina de vidro padrão e fixou-se em álcool absoluto para posterior coloração segundo a técnica de Papanicolaou.

Obteve-se anti-sepsia com tintura de polivinilpirrolidona-iodo e realizou-se laparotomia mediana. Inventariou-se a cavidade abdominal, pois animais com doenças seriam desprezados e identificaram-se os ovários. Realizou-se a secção do mesoovário entre ligaduras feitas com fio de categute simples 3.0, com retirada dos ovários bilateralmente e revisão da hemostasia. Fez-se a laparorrafia com 2 planos de síntese: o primeiro, peritônio-músculoaponevrótico; e o segundo, o da pele. Para ambos os planos utilizou-se fio 4.0 monofilamentar de náilon.

Seccionou-se longitudinalmente o ovário direito em sua região mediana em duas partes; uma reservou-se para reimplante e a outra, fixou-se em formol a $10 \%$ encaminhou-se para estudo histológico com a finalidade de obter informação do padrão ovariano. Desprezou-se o ovário esquerdo.

Nos animais do controle, retiraram-se os ovários e uma secção do tecido ovariano foi reservada para estudo histológico.

Procedeu-se à anti-sepsia da região inguinal direita dos animais destinados ao experimento, e incisou-se a pele e a tela subcutânea por $2,0 \mathrm{~cm}$, sobre a prega inguinal. Identificaram-se os vasos femorais e junto deles implantou-se a metade do ovário, fixando-o na posição com um ponto frouxo de fio monofilamentar de náilon 6.0. Aproximou-se a tela subcutânea e fez-se a síntese da pele com chuleio contínuo de náilon 6.0. Recuperados da anestesia, devolveram-se os animais às suas caixas, onde permaneceram até a data prevista para a aferição.

Decorridos 28 dias procedeu-se à nova anestesia pelo método já descrito e colheu-se novo esfregaço vaginal (momento 1).

Em seguida incisou-se a pele sobre a prega inguinal direita no local da cicatriz anterior localizou-se o implante ovariano, que foi ressecado e fixado em formol a $10 \%$ para estudo histológico.

Submeteram-se os animais à eutanásia com dose letal inalatória de éter etílico.

Prepararam-se os esfregaços vaginais dos momentos 0 e 1 pelo método de Papanicolaou e neles avaliou-se o trofismo vaginal assim classificado: estro, proestro, diestro e metaestro.

Os esfregaços em estro, metaestro e proestro indicam indiretamente a influência hormonal de estrogênio e os em diestro determinam a não influência hormonal.

Prepararam-se os segmentos ovarianos encaminhados para estudo histológico no momento 0 e no momento 1 . Fizeram-se cortes longitudinais com 5 micrômetros de espessura que foram corados pelo método da Hematoxilina e Eosina. Nestes cortes estudou-se a presença de folículos que foram classificados em primordiais, primários e secundários.

Recorreu-se à análise descritiva dos dados através de tabelas, quadros e gráficos. Para a comprovação dos objetivos levantados neste trabalho utilizaram-se os testes paramétricos "t de Student" e os não-paramétricos “Mann-Whitney”, e "Wilcoxon"do software "Primer of Biostatistics" . Empregaram-se ainda os testes do "Qui-Quadrado com correção de Yates" e "Exato de Fisher" do Epi-Info. Adotou-se $\mathrm{p}=0,05$ ou $5 \%$ como nível para rejeição da hipóteses de nulidades.

\section{Resultados}

Analisando-se a citologia vaginal no momento 0 verificou-se, no grupo $\mathrm{A}$, as fases de metaestro $(63,6 \%)$ e estro $(36,4 \%)$ e, no grupo $\mathrm{B}$, as fases de estro $(58,3 \%)$ e metaestro $(41,7 \%)$; portanto $100 \%$ dos esfregaços mostravam células que estavam sob influência estrogênica (GCE). No Momento 1, todas as ratas do grupo A forneceram esfregaços em fase de estro $(\mathrm{p}=0,001)$, isto é, com influência estrogênica, (Figura 1) e a maioria das do Grupo $\mathrm{B}$, em diestro $(83,3 \%)(\mathrm{p}=0,002)$, ou seja, células sem a influência estrogênica (Figura 2).

O exame histológico do tecido autotransplantado recuperado permitiu verificar a presença de folículos primordiais, que se constituem de uma camada de células granulosas esparsas ao redor do oócito; folículos primários, com uma ou duas camadas de células cubóides; folículos secundários (pré-antrais e antrais), formados de três ou mais camadas de células granulosas circulando o oócito e apresentando uma cavidade antral no estágio mais desenvolvido.

Em relação ao predomínio folicular observado nos cortes histológicos dos ovários das ratas do grupo $\mathrm{A}$, nos momentos $0 \mathrm{e}$ 1 , não se constatou diferença significante (Tabela 1). 


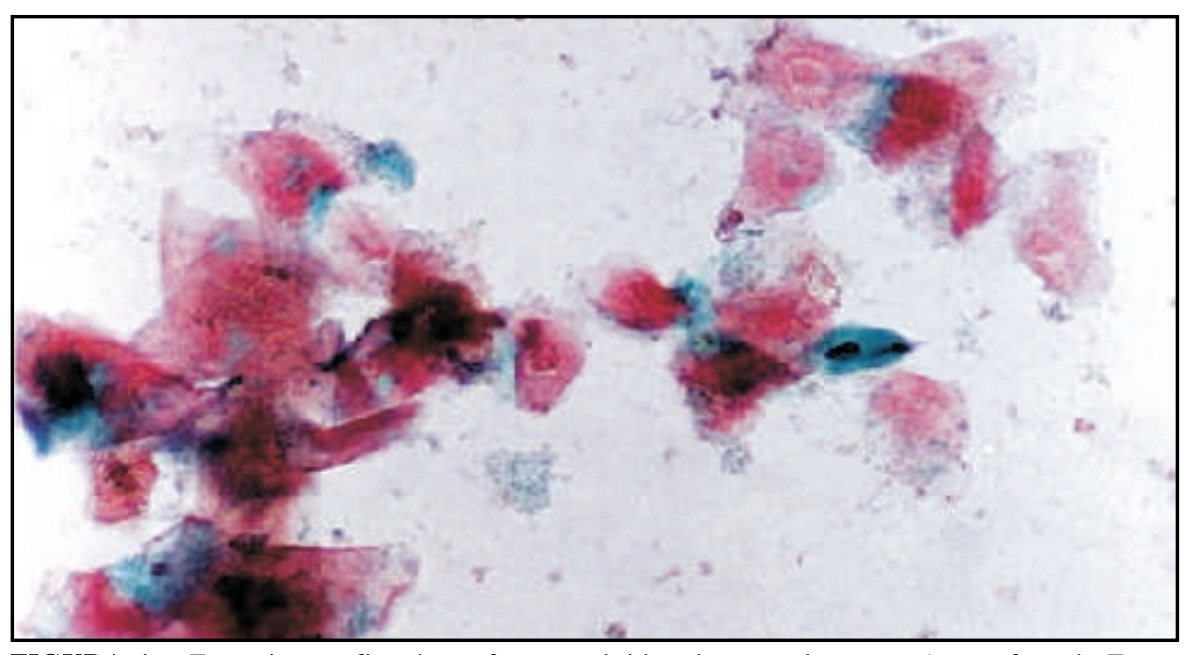

FIGURA 1 - Fotomicrografia de esfregaço obtido de rata do grupo A, em fase de Estro, representado por células superficiais, com aspecto orangiófilo e anucleadas, poucas células nucleadas e ausência de polimorfonucleares.

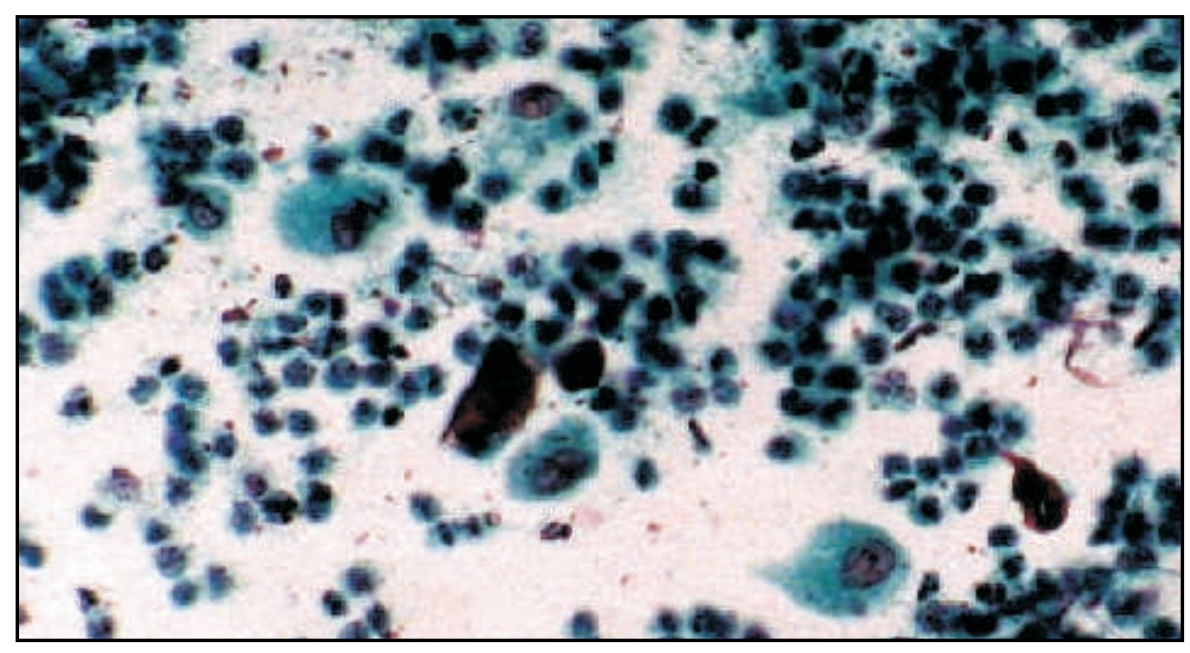

FIGURA 2 - Fotomicrografia de esfregaço vaginal obtido de rata do grupo B, no momento 1, em fase de diestro, representado por pouquíssimas células cornificadas. Observam-se células basais e invasão de polimorfonucleares.

TABELA 1 - Predomínio folicular nos momentos 0 e 1 do grupo A

\begin{tabular}{c|l|c|c|c|c|c}
\hline \multirow{2}{*}{$\begin{array}{c}\text { PREDOMÍNIO } \\
\text { FOLICULAR }\end{array}$} & \multicolumn{2}{|l|}{ MOMENTO 0} & \multicolumn{2}{|c|}{ MOMENTO 1 } & \multicolumn{2}{|c}{ ESTATÍSTICA $^{(1)}$} \\
\cline { 2 - 7 } & $\mathrm{N}^{\circ}$ & $\%$ & $\mathrm{~N}^{\circ}$ & $\%$ & Probabilidade & Significância \\
\hline Primordiais & 03 & 20,0 & - & - & $\mathrm{p}=0,1121$ & $\mathrm{NS}$ \\
\hline Primários & 03 & 20,0 & 04 & 26,7 & $\mathrm{p}=0,5000$ & $\mathrm{NS}$ \\
\hline Secundários & 05 & 33,3 & 08 & 53,3 & $\mathrm{p}=0,4612$ & $\mathrm{NS}$ \\
\hline Sem Predomínio & 03 & 20,0 & 02 & 13,3 & $\mathrm{p}=0,5000$ & $\mathrm{NS}$ \\
\hline Sem Avaliação & 01 & 6,7 & 01 & 6,7 & $\mathrm{p}=0,7586$ & $\mathrm{NS}$ \\
\hline TOTAL & 15 & 100,0 & 15 & 100,0 & - & - \\
\hline
\end{tabular}

(1) Aplicado o teste de "Fisher".

\section{Discussão}

No transplante heterotópico subcutâneo de ovário para a região interna do braço esquerdo de uma paciente, relatado por Leporrier e col. (1987), o ovário transplan-
Vários autores concluíram que enxertos ovarianos são viáveis. Nance e col. (1983), comparando os transplantes ovarianos uni e bilaterais, em ratas, relataram que, embora tivessem produção hormonal, encontraram alterações cíclicas de estrogênio e dos níveis de FSH e LH, sugerindo que os mecanismos de controle endócrino estavam alterados ${ }^{10}$. Gosden e col. (1994) realizaram enxertos de ovário de ovelhas em camundongos e observaram que o tecido ovariano não apenas mantinha a viabilidade como apresentava folículos em vários estágios de desenvolvimento ${ }^{7}$. Guanasena e col. (1997) efetuaram o alotransplante de tecido ovariano murino a fresco e criopreservado e demonstraram a manutenção da função endócrina dos enxertos, verificada pela recuperação do ciclo estrogênico ${ }^{8}$.

No que se refere ao sítio de colocação do enxerto, vários foram descritos: na região cervical de ratos ${ }^{5}$, bursa ovariana de ratos $^{1}$, subcutâneo do dorso de ratos $^{3}$, sob a cápsula renal ${ }^{11}$, subcutâneo da parede abdominal de cadelas ${ }^{6}$. Parece que o importante e colocar o enxerto próximo de grandes vasos, em áreas que facilitem a neovascularização.

No presente estudo foi possível verificar que no momento 0 todos os esfregaços vaginais monstraram a citologia em fase de metaestro ou estro, definindo que estes animais estavam sob influência estrogênica. Já no momento 1 os esfregaços das ratas do grupo A estavam em fase de estro, isto é, sob influência hormonal enquanto os do das ratas do grupo B estavam em fase de diestro, ou seja, sem influência hormonal. Desta forma ficou evidente que os ovários transplantados mantinham sua função endócrina.

O estudo histológico dos cortes de ovário, nos momentos 0 e 1 , para os animais do grupo A, demonstrou presença de folículos, em diferentes estágios de desenvolvimento, variando o predomínio de cada tipo celular, em 100\% das amostras analisadas, um claro indício da viabilidade dos tecidos.

\section{Conclusão}

O autotransplante subcutâneo de tecido ovariano bisseccionado, em região inguinal de ratos, mostrou ser uma técnica que preserva tanto a viabilidade quanto a 
funcionabilidade do tecido ovariano transplantado, em ratas.

\section{Referências}

1. Aubard Y, Newton H, Scheffer G, Gosden R. Conservation of the follicular population in irradiated rats by the cryopreservation and orthotopic autografting of ovarian tissue. Eur J Obst Gynecol Rep Biol 1998; 79:83-7.

2. Bomford CK, Kunkler IH, Sherriff SB. Walter's and Miller's textbook of radiotherapy. 5ed. New York: Churchill Livingstone; 1993.

3. Corleta HVE, Corleta o, Capp E, Edelweiss MI. Subcutaneous autologous ovarian transplantation in Wistar rats maintains hormone secretion. Fert Steril 1998; 70:16-9.

4. D'Acampora AJ, Manoel FS, Schmidt RR, Muller CT, Tognoli H, Oliveira A, Raymundi
SD, Tramonte R. Análise histológica da viabilidade do transplante ovariano para retroperitônio de ratas. ACM Arq Catarin Méd 2000; 29:72-3.

5. Dissen GA, Lara HE, Fahrenbach WH, Costa ME, Ojeda SR. Immature rato varies become revascularized rapidly dependent increase in angiogenic factor gene expression. Endocrinol 1994; 134:114654.

6. Ferreira da Silva KSB. Avaliação da efetividade do autotransplante de ovário em tecido subcutâneo de cadelas [Dissertação Mestrado]. Universidade Federal do Paraná - Universidade Regional de Blumenau; 2000.

7. Gosden RG, Baird DT, Wade JC, Webb R. Restoration of fertility to oophorectomized sheep by ovarian autografts stored at $-196^{\circ}$ C. Hum Reprod 1994; 9:597-603.

8. Guanasena KT, Lakey JRT, Villines PT, Critser ES, Critser JK. Allogenic and xenogenic transplantation of cryopreserved ovarian tissue to athymic mice. Biol Reprod 1997; 57:226-31.

9. Leporrier M, Theobald PV, Roffe JL, Muller G. A new technique to protect ovarian function before pelvic transplantation: heterotopic ovarian autotransplantation. Câncer 1987; 60:2201-4.

10. Nance DM, Moger WH, Wilkinson M Neuroendocrine control of ovarian autografts. End Res Commun 1983; 9:18594.

11. Oktay K, Newton H, Mullan J, Gosden RG. Development of human primordial follicles to antral stages in SCID/hpg mice stimuled with follicle stimulating hormone. Hum Reprod 1998; 13:1133-8.

12. Weissman A, Gotlieb L, Colgan T, Jurisicova A, Greenblatt EM, Casper RF. Preliminary experience with subcutaneous human ovarian córtex transplantation in the NODSCID mouse. Biol Reprod 1999; 60:1462-7.

Ceschin AP, Biondo-Simões MLP, Thomaz BAC, Totsugui J. Indirect hormonal evaluation and study of the follicles preservation in the ovarian transplantation tissue in rats inguinal region. Acta Cir Bras [serial online] 2004 JanFeb;19(1). Available from URL: http://www.scielo.br/acb.

ABSTRACT - Purpose: To analyse the effectivity technique of the subcutaneous autologous bisseccionated ovarian transplantation technique in inguinal region of the albine rats, close to the femoral vases, through the indirect study of hormonal production, made by the evaluation of the citology of the vaginal smears and the direct study of the tissue viability, carried out by histologic analysis. Methods: 30 rats were analysed which suffered bilateral ooforectomy, being 15 of them intended for control and 15 of them suffered the ovarian transplantation. After 28 days, the grafting were recovered and evaluated. The analysis of the cytology of the vaginal smears were made in the moment 0 , that is to say, pre-transplantation, and in the moment 1 , post-transplantation, for all the animals and the histologic evaluation was accomplished at the moment 0 for the two groups and at the moment 1 for the animals that suffered transplantation. Results: The results of the experiment demonstrated the viability and functionality of the grafts in $100 \%$ of the laminas evaluated, that were observed through the vaginal smears in estrous phase to all the rats of the experience group and by the presence of follicles in various stages of maturation, observed in the recovered grafts, indicating, directly, the viability of the ovarian tissue. Conclusion: Allowing to conclude that the ovarian transplantation is a viable alternative, in the conditions of the experiment, to the hormonal and follicular preservation in rats.

KEY WORDS - Ovary. Transplantation. Hormones. Estrogens. Progesterone. Rats.

Conflito de interesse: nenhum Fonte de financiamento: nenhuma

Correpondência

Maria de Lourdes Pessole Biondo-Simões

Rua Ari José Valle, 1987

82030-000 Curitiba - PR

Tels: (41) 297-4359/9991-55 66

biondo@avalon.sul.com.br

Data do recebimento: 30/09/2003

Data da revisão: 13/10/2003

Data da aprovação: 03/11/2003 